\title{
COMMUNICATIONS
}

\section{PROLIFERATION OF LIMBAL MELANOBLASTS INTO THE CORNEA IN RESPONSE TO A CORNEAL LESION*}

\section{AN EXPERIMENTAL STUDY}

BY

\section{C. MICHAELSON}

Haifa, Israel

WHEN an artificial lesion is made in the cornea of the rabbit, there is besides an intrusion of the new blood vessels from the limbus, a proliferation or " sliding" of conjunctival epithelial cells including pigment cells into the cornea. This has been observed by Mann and Pullinger (1943), Maumenee and Scholz (1948), and Campbell and Michaelson (1949).

The following report indicates that proliferation of the limbal melanoblasts into the cornea is apparently, under certain circumstances, a constant reaction to an experimental lesion of the cornea in the rabbit; that the proliferation has certain features in common with the vascular proliferation and occurs at the same time; and that both proliferations are probably due to the same stimulus. It incidentally indicates possibilities of studying factors which may effect the elaboration of pigment in pigment cells.

\section{Method}

A large number of observations were available because they could be obtained from the control eyes (left eyes) in a series of experiments carried out for other purposes. The following preparations were available for observation:

(1) Preparations of rabbit corneae prepared in the following manner: a lesion was placed in the cornea by means of an electro-cautery $2.0-3.0 \mathrm{~mm}$. from the limbus at 12 o'clock. The wound was about $1.2 \mathrm{~mm}$. in diameter and included about two-thirds of the corneal thickness. The lesion was standardized by supplying the cautery with a fixed voltage and applying it for a fixed time. The cauterization was renewed each day for a period of 4-10 days. On the final day the animal was given a lethal dose of prodormol. Immediately thereafter, an injection of India ink under pressure was made into the carotid arteries, thereby demarcating in most cases the new-vessel proliferation into the cornea. The appropriate pieces of the corneae were then cleared, mounted in glycerine, and examined on the flat with a stereoscopic microscope, using a magnification of $\times 17$. After this examination several of the corneal pieces were embedded in paraffin, sectioned, and stained with haemalum and eosin. In this way 100 corneal preparations were made available for observation. They were all from left eyes which had been used as controls, and had received no treatment except subconjunctival injection of a bland substance such as normal saline.

(2) Preparations similar to the above were obtained from corneae which had been treated with $x$ radiation during the period of ulcer production or immediately after cauterization had been stopped. In all cases a total of $1,500 \mathrm{r}$, divided into three to six doses, had been given. These eyes represented the paired right eyes of some of the hundred left eyes used as controls.

* Received for publication July 30, 1952. 


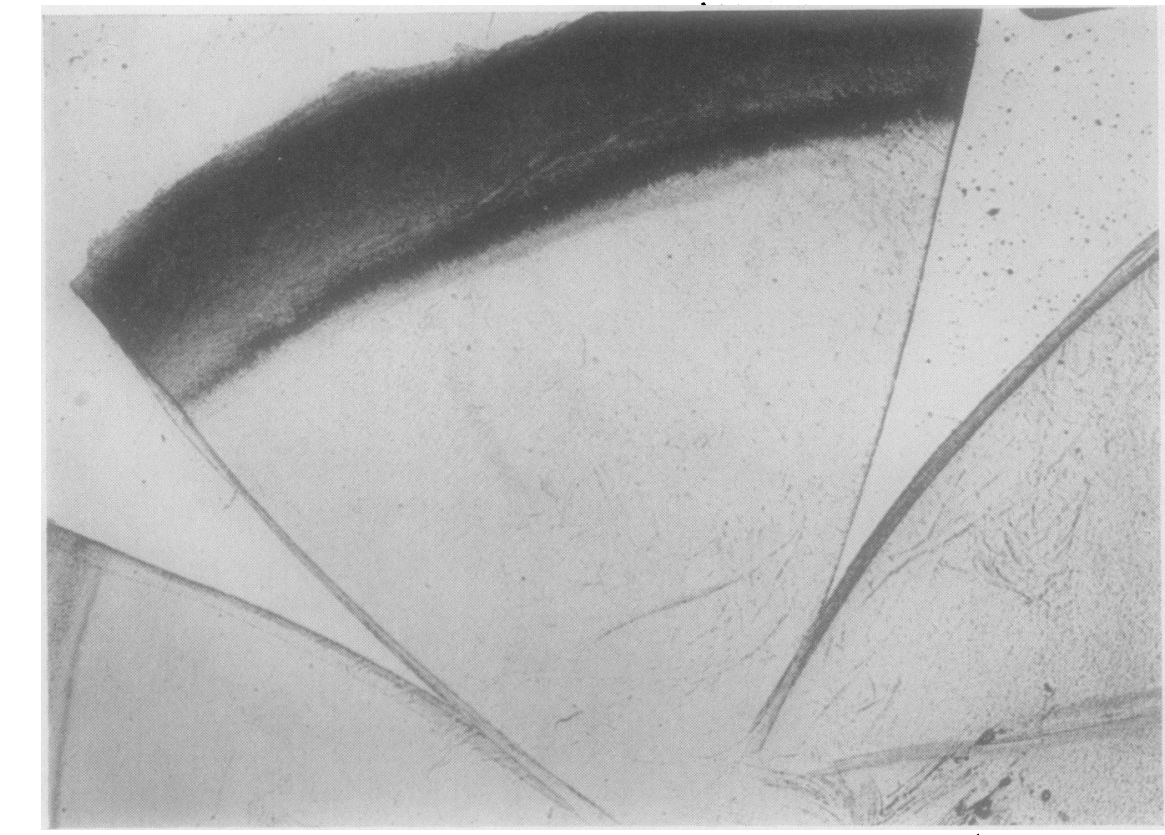

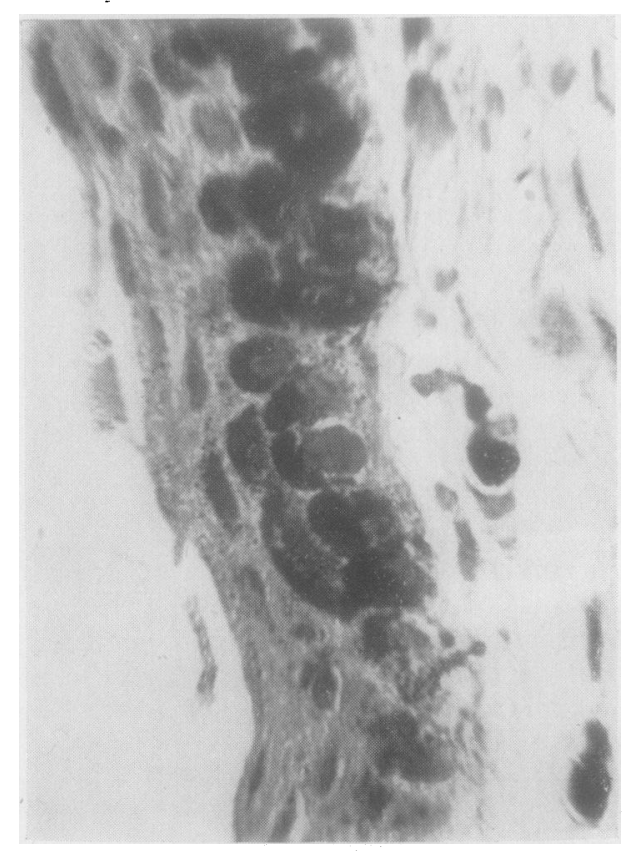

FIG. 2.-Section of pigment band at limbus. The melanoblasts lie chiefly in the basal layer of the conjunctival epithelium. In this position the pigment appears in the form of a clump, lying like a cap at the side of the cell nucleus directed towards the surface of the epithelium.
Fig. 1.-Normal pigment band around limbus of cornea in the rabbit $(\times 9)$.

\section{Results}

In interpreting the results the following points must be noted. Around the limbus in the rabbit there is a well-marked and often dense band of pigment-containing cells (Figs 1 and 2). Most of the pigment is contained in melanoblasts situated in the basal layer of the conjunctival epithelium. In the superficial layers fine dots of pigment are present, whereas in the basal layer the pigment is in the form of a clump, frequently lying like a cap on the side of the cell nucleus directed towards the surface of the epithelium. In man there are similarly situated cells but the pigment content varies according to race (Redslob, 1922).

In the normal rabbit there are 


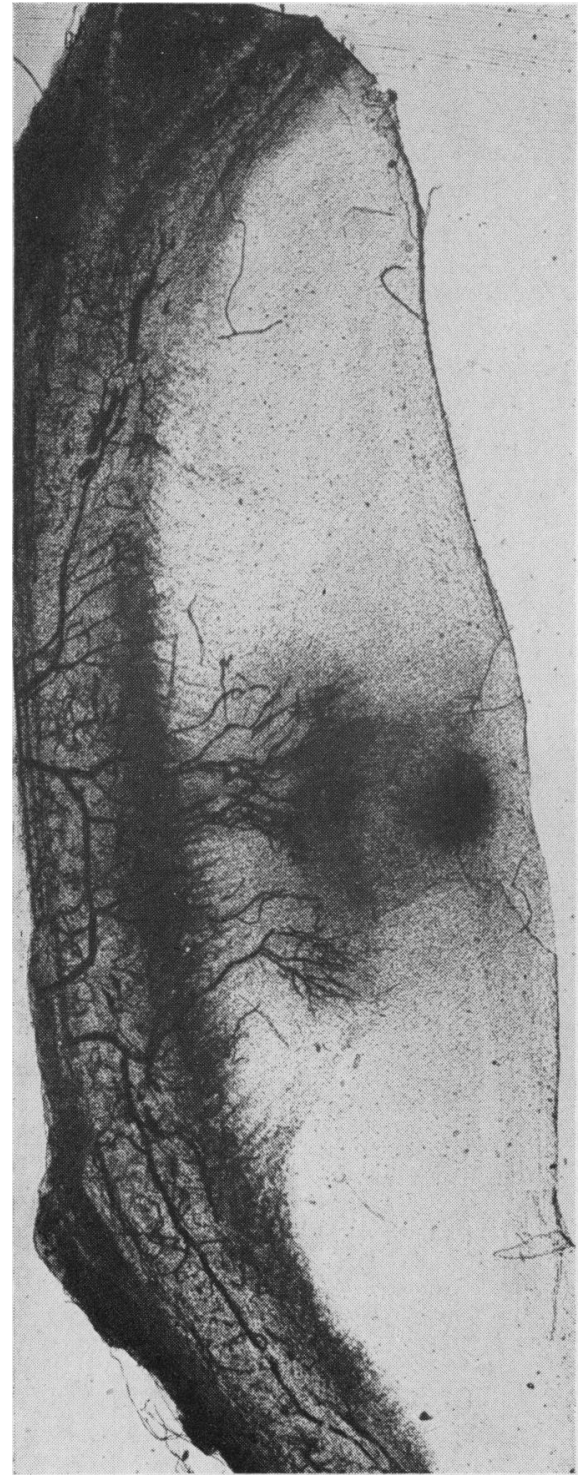

Fig. 3(a).-Cornea examined on the flat, showing corneal wound, and associated illinjected vascular triangle. Co-extensive with this triangle a pigment proliferation has taken place from the limbal pigment band. The poor injection of the vascular triangle enables the pigment triangle to be seen more clearly $(\times 11)$. often local areas where this pigment band narrows and in places there may even be a gap in it. These gaps and areas of narrowing are not confined to any particular region of the band. The normal cornea contains no pigment cells.

\section{Untreated Corneae}

(1) In eighteen of these corneae (18 per cent.) there was pigment present, easily observable with a magnification of $\times 17$ within the triangular area of the new-vessel formation (Figs $3 a$ and $b$ ). The pigment is always fairly closely confined to this triangular vascular area, with its base at the

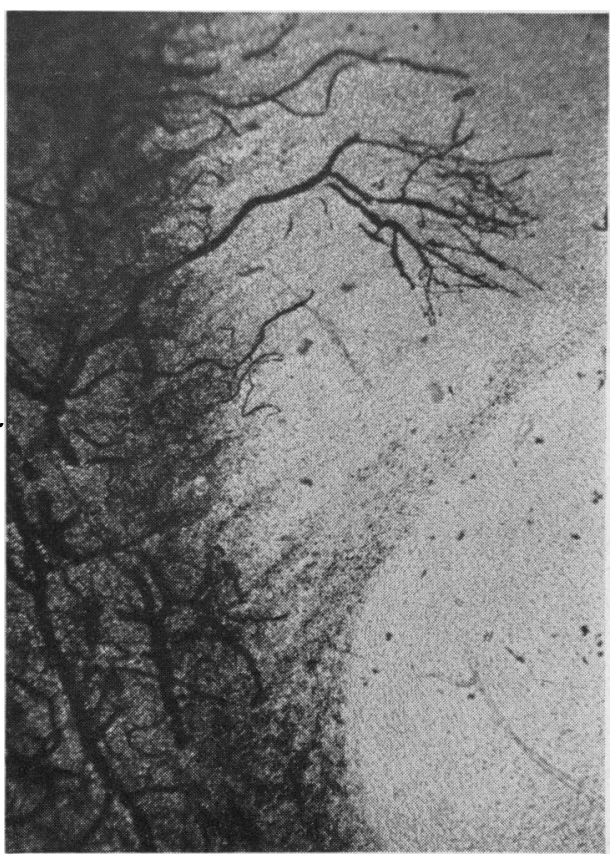

FIG. 3(b).-Higher magnification of section of Fig. 3(a), showing one basal angle of pigmentvascular triangle $(\times 25)$.

limbus and its apex directed towards the corneal wound. In the majority of corneae in this group, however, no pigment was discernible in the vascularized 
area with the magnification used (Fig. 4).

(2) A gap in the limbal pigment ring was noted in 80 per cent. of the preparations, using a magnification of $\times 17$. The gap was opposite the base of the area of vascularization or pigment intrusion (Fig. 5).

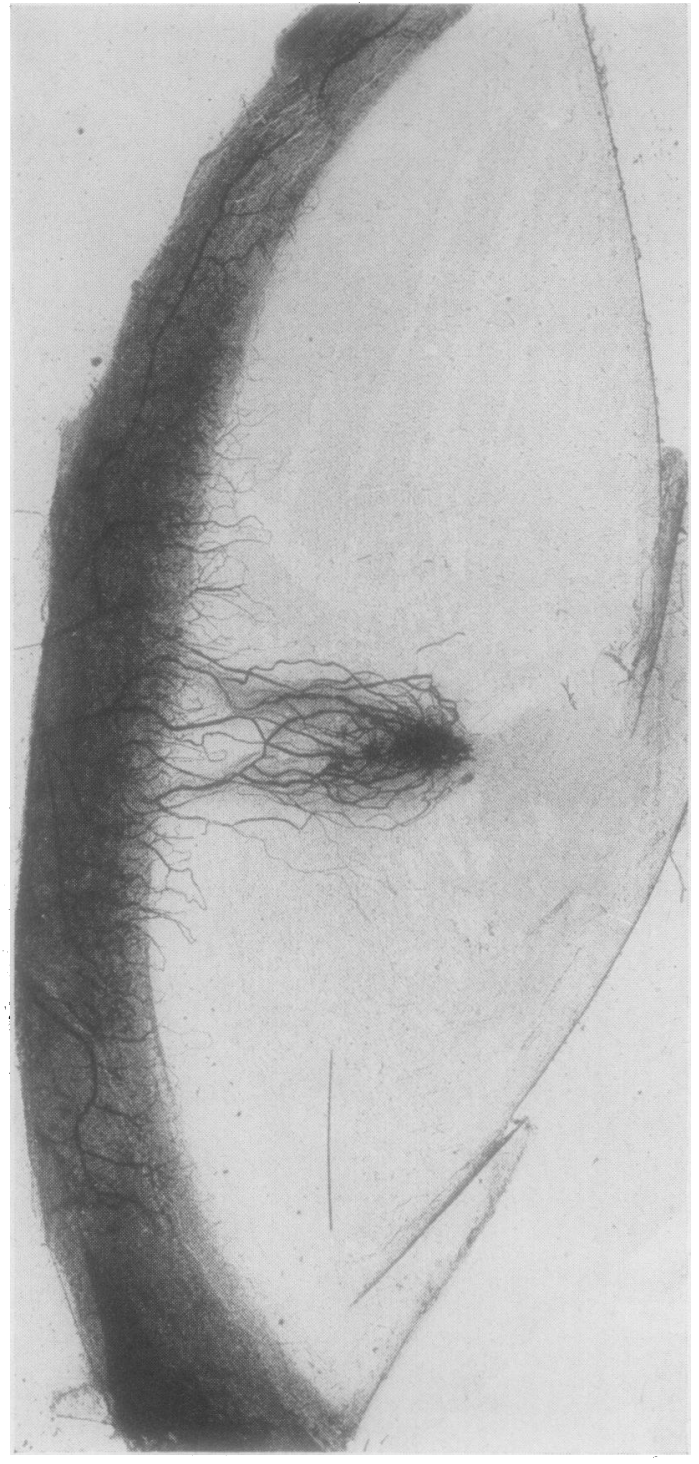

Fig. 4.-Corneal wound with triangular area of $n \mathrm{w}$ blood vessels $(\times 9)$. No pigmentation visible with a magnification of $(\times 17)$.

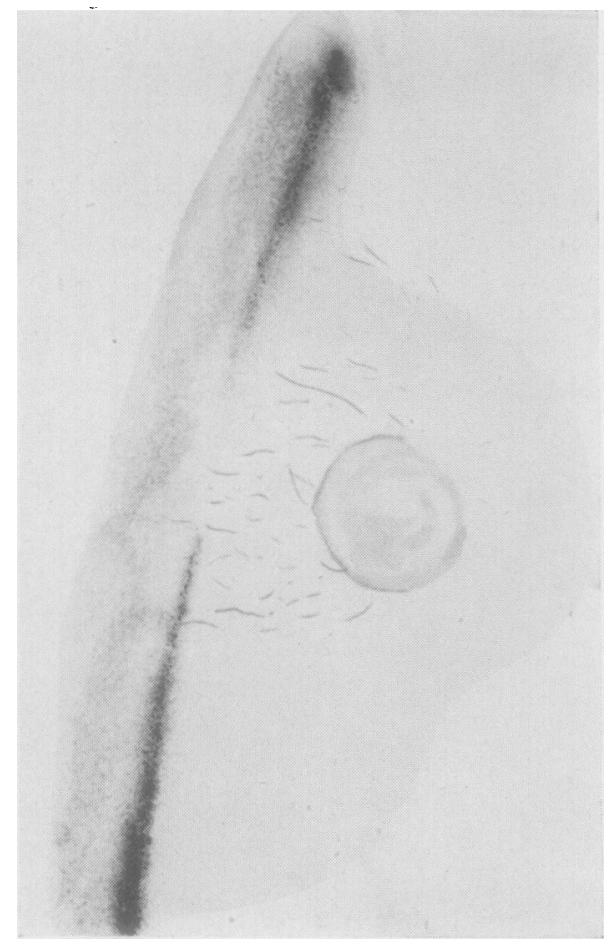

FIG. 5.-Gap in limbal pigment ring opposite site of injury.

(3) Sections of one of the corneae with observable pigmentation show that the pigment is contained in cells situated in the epithelium superficially to the pannus (Fig. 6, opposite). The pigment is seen lying chiefly in the deeper cells of the epithelium situated around the outer pole of the nucleus as already noted above in the limbal epithelium. One or two pigment cells can be seen in the superficial layers of the propria. The superficial epithelial cells contain very fine pigment dots. This appearance was also observed in the sections of several corneae in which no pigmentation was seen with the flat preparations at a magnification of $\times 17$. 


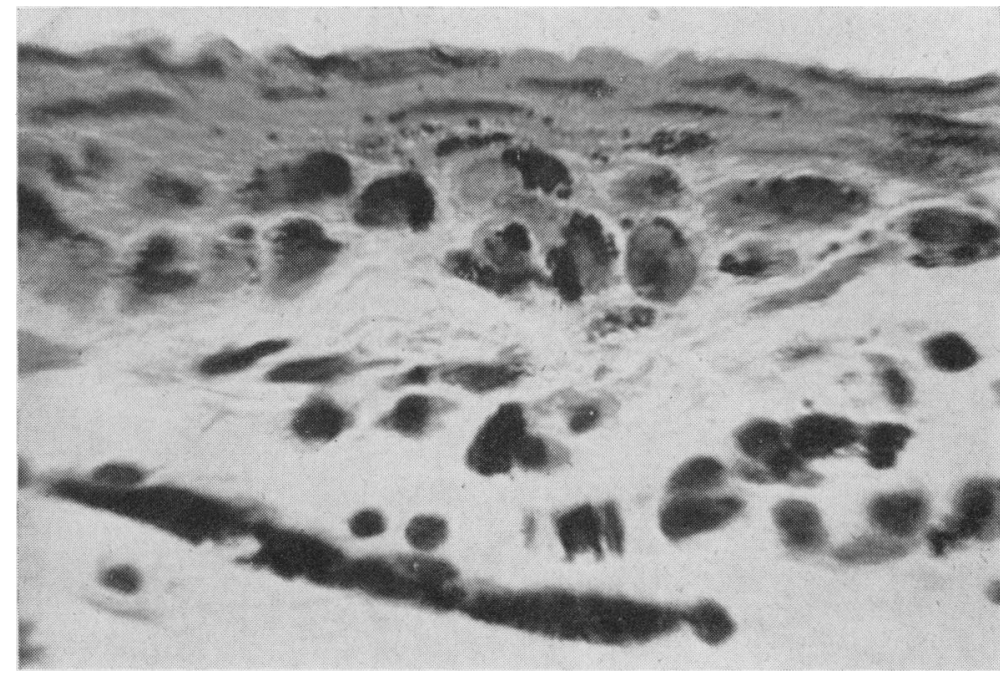

FIG. 6.-Section of cornea from area showing pigment and vascular intrusion. The pigment lies chiefly in the deeper epithelial layers. One or two pigment cells can be seen in the superficial layers of the propria. The superficial cells of the epithelium contain fine pigment dots. The linear dark mass lying in the propria is a blood vessel filled with ink.

(4) When the lesion was $4 \mathrm{~mm}$. or more from the limbus, neither pigment cell nor vascular proliferation took place from the limbus.

It may be concluded from these observations that proliferation of the limbal melanoblasts takes place in response to a lesion placed in the cornea within a critical distance from the limbus and that this proliferation takes place over an extent roughly corresponding to the vascular proliferation. This process appears to take place regularly if one can judge from the interruption in the pigment band which occurs in the vast majority of eyes. The melanoblasts which proliferated into the cornea tended to lose their pigment, however, and only in about 18 per cent. of eyes is the pigment content of the proliferated cells such as to be discernible with the magnification used with the flat preparations.

There is evidence that the proliferation of conjunctival limbal epithelial cells is not confined to melanoblast cells (Maumenee and Scholz, 1948). The process has been described as a "sliding" of the limbal cells (Mann and Pullinger, 1943), but, since the intrusion into the cornea in many cases much more extensive than the original narrow pigment band at the limbus, it may be assumed that there is an actual proliferation of the pigment cells in the direction of the corneal wound. As the pigment under the magnification used was discernible in only 18 per cent. of the corneae, it would appear that the melanoblasts tend to lose their pigment in the conditions of rapid proliferation. The results reported from these eyes which received radiation show that such cells may become re-pigmented. 


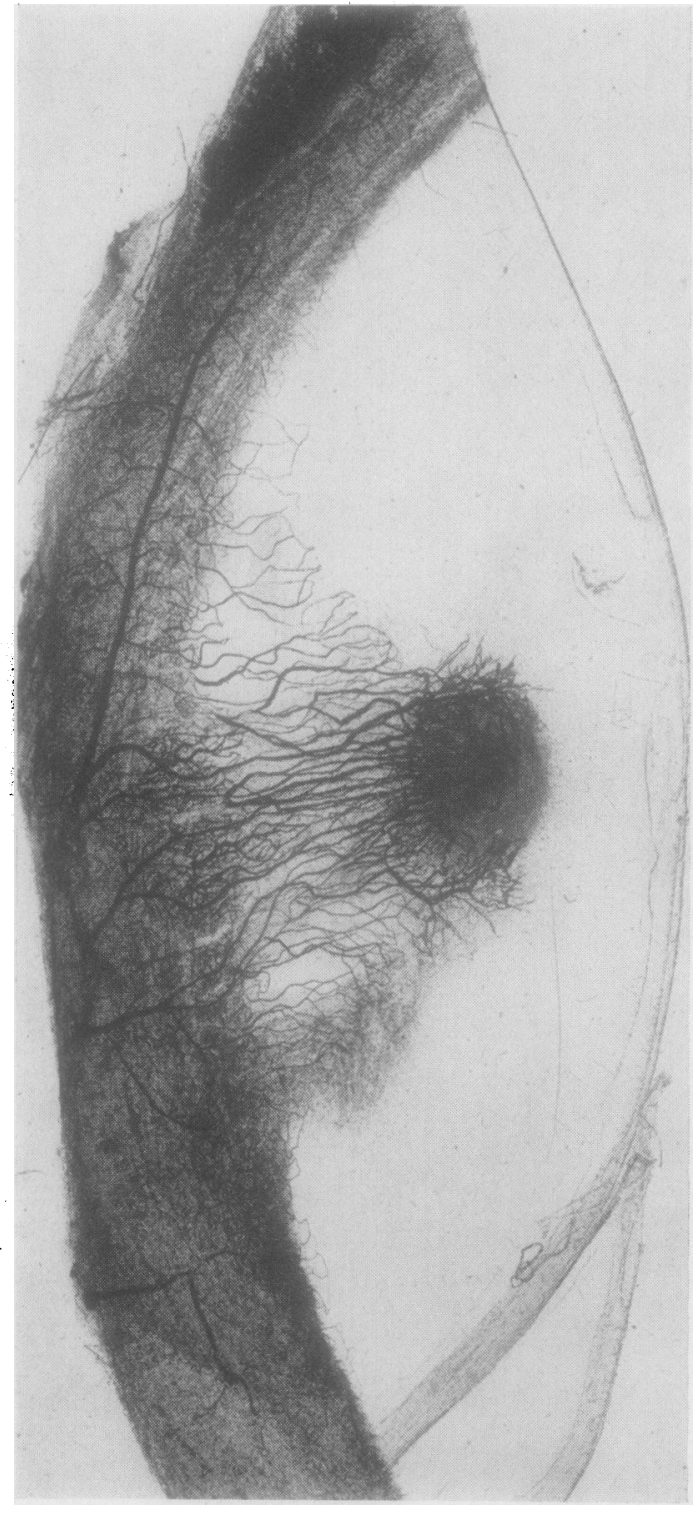

FIG. 7.-Corneal wound with triangular infiltration of blood vessels and pigment $(\times 9)$.

\section{Corneae treated with $x$ Radiation}

(1) In 27 of these corneae (92 per cent.), pigmentation was discernible with a magnification of $\times 17$ (Figs 7, 8, and 9). Because of the greater number of eyes with better pigmented corneae in this group, it is possible to draw further conclusions regarding the relationship between the pigment and the vascular triangles. In some cases the base of the pigment triangle appears to be slightly larger than that of the vascular triangle. In some cases the height of the vascular triangle is greater than that of the pigment triangle, while in some it is less. Some of these differences may be merely apparent and due to insufficient pigmentation of the potential melanoblasts by the radiation or to insufficient filling of the new capillaries with ink. It may be concluded that the pigmented and vascular triangles have similar positions and shapes, although sizes may differ. The similarities and differences between the vascular and pigmented triangles is well indicated in Figs 10 and 11 (overleaf); here the vascular triangle happened to be rather unusual, with a shortened base eccentric to a vertical line dropped from the wound to the limbus. The pigmented triangle shows precisely the same eccentricity of formation, but the pigment proliferation has advanced farther into the cornea.

(2) A gap in the limbal pigment ring was noted in 81 per cent. of the preparations, using a magnification of $\times 17$.

The similarity between the number of cases showing a pigment limbal gap in the untreated and radiated groups indicates that the proliferation of pigment cells into the cornea occurred in the radiated eyes with a frequency 
Fig. 8.-Pigment intrusion into the cornea directed towards a corneal wound not seen in the illustration. The breaking up of the pigment band opposite the area of intruis well seen $(\times 25)$.
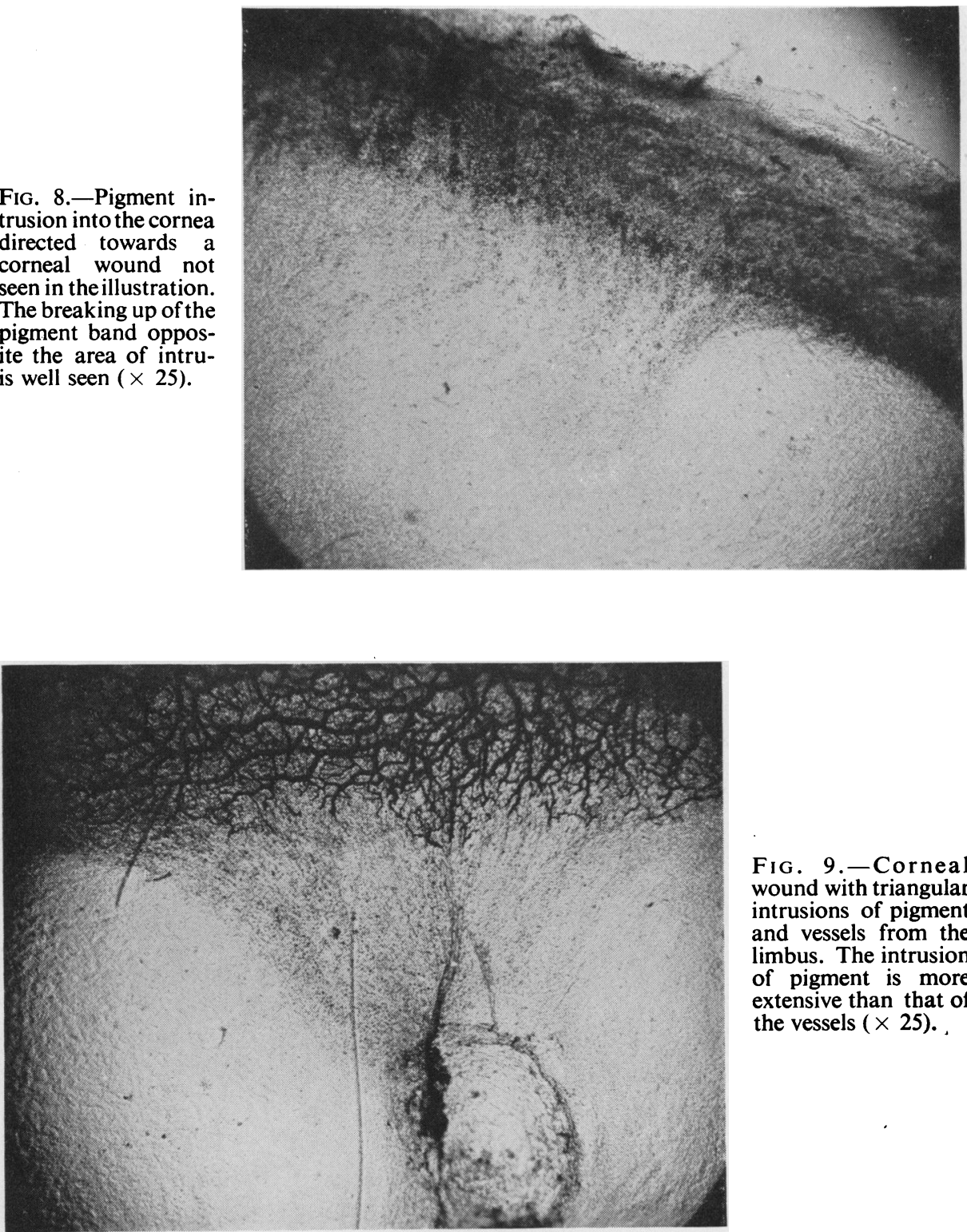

FIG. 9.-Corneal wound with triangular intrusions of pigment and vessels from the limbus. The intrusion of pigment is more extensive than that of the vessels $(\times 25)$.

similar to that with which it occurred in the untreated eyes. The disparity between the percentages of cases showing pigment in the cornea in the radiated and untreated eyes ( 92 per cent. as against 18 per cent.) indicates that pigment cells quickly resume their capacity to form pigment under the influence of the radiation. It is well known that radiation may activate the formation of melanine in potential melanoblasts. 


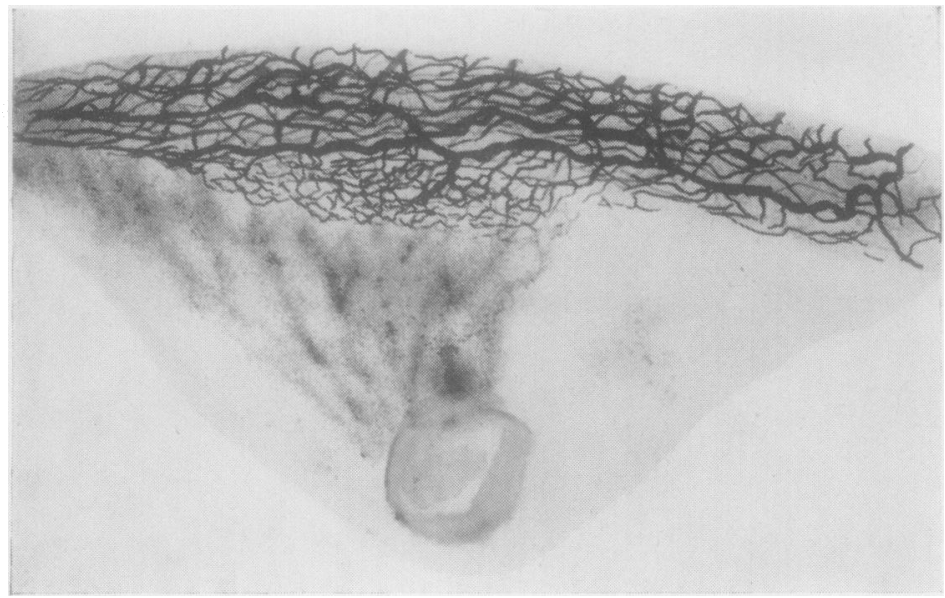

Fig. 10.-Vessel and pigment infiltrations into the cornea are similarly asymmetrical to a vertical line dropped from the wound to the limbus.

Fig. 11.-Higher power of a section of Fig. 10 $(\times 25)$.

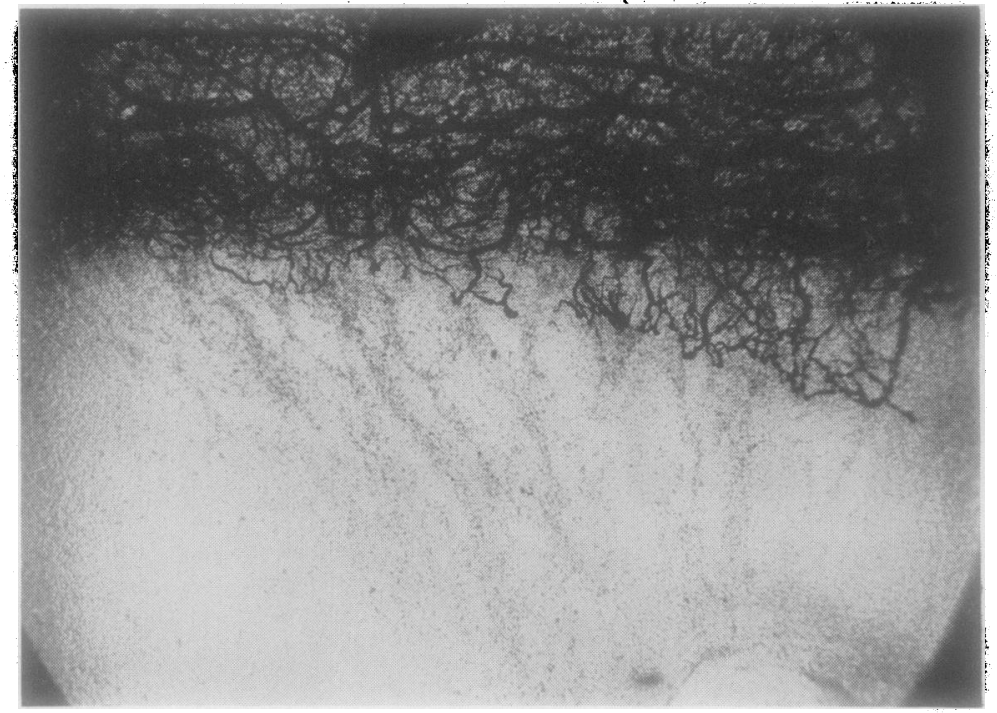

Discussion

The similarities in shape and position of the triangular area of pigment cell proliferation into the cornea with that of new vessel proliferation which occurs at the same time, indicates that the mechanisms initiating the two processes are possibly similar. It has been suggested that the new vessel formation is stimulated by a factor formed at the site of the corneal injury which is capable, after diffusing through the cornea, of stimulating the budding of the limbal capillaries 'Campbell and Michaelson, 1949). The triangular distribution of the proliferated pigment cells with the apex directed towards the corneal lesion indicates that a similarly operating factor may affect the 
pre-existing cells at the limbus. The cells tend to lose their pigment in the process of rapid proliferation, but can be induced to re-elaborate it under the influence of radiation. The possibility of inducing pigment-containing cells to migrate across a sharp boundary into a transparent and therefore easily observed territory normally free from pigment cells, the fact that such cells frequently lose their pigment in the process, and the possibility of stimulating a measurable degree of re-pigmentation open up the possibility of studying factors which may influence the elaboration of pigment in melanoblasts.

Although this communication confines itself to the behaviour of the melanoblasts at the limbus in response to a corneal injury, it is probable that the other epithelial limbal cells behave in a comparable fashion.

\section{Summary}

(1) Pigment cell proliferation from the limbus into the cornea was studied in 100 rabbit eyes in which a standard lesion was placed within $2-3 \mathrm{~mm}$. of the limbus. Although in the flat preparations with the magnification used $(\times 17)$ pigment was found in only 18 per cent. of these corneae, the presence of a gap in the normal pigment band at the limbus in the great majority of the eyes indicates that pigment cell proliferation into the cornea is a normal response to this type of wound.

(2) The effect of $x$ radiation $(1,500 \mathrm{r}$ in divided doses) upon the pigment cells proliferating into the cornea was studied in 29 rabbit eyes which had received a standard lesion similar to the above. The presence of pigment in almost all the corneae examined supports the idea that pigment cells proliferate regularly in such circumstances, and indicates the ease with which the newly proliferated cells can be induced to re-elaborate their pigment.

(3) Certain similarities in the distribution of the pigment cell proliferation and the new vessel proliferation into the cornea indicate that a similar factor induces both. This factor may be material elaborated at the site of the injury and diffused through the cornea to the limbus.

(4) The measurable proliferation of pigment cells into a territory normally transparent and non-pigmented opens up the possibility of studying factors which may influence the elaboration of pigment in pigment cells.

This work has been supported by a grant from the National Council to Combat Blindness, New York. The technical work was performed by Miss Eva Lewkowitz.

\section{REFERENCES}

Campbell, F. W., and Michaelson, I. C. (1949). British Journal of Ophthalmology, 33, 248.

ManN, I., and Pullinger, B. D. (1943). Amer. J. Ophthal., 26, 1253.

Maumenee, A. E., and Scholz, R. O. (1948). Bull. Johns Hopk. Hosp., 82, 121.

Redslob, E. (1922). Ann. Oculist., Paris, 159, 523. 